Late gestation over- and undernutrition predispose for visceral adiposity in response to a post-natal obesogenic diet, but with differential impacts on glucose-insulin adaptations during fasting in lambs

Khanal, Prabhat; Husted, Sanne Vinter; Axel, Anne Marie Dixen; Johnsen, Lærke; Pedersen, Kasper Lykke; Mortensen, Martin Steen; Kongsted, Anna Hauntoft; Nielsen, Mette Olaf

Published in:

Acta Physiologica (Print)

DOI:

10.1111/apha.12129

Publication date:

2014

Document version

Early version, also known as pre-print

Citation for published version (APA):

Khanal, P., Husted, S. V., Axel, A. M. D., Johnsen, L., Pedersen, K. L., Mortensen, M. S., Kongsted, A. H., \& Nielsen, M. O. (2014). Late gestation over- and undernutrition predispose for visceral adiposity in response to a post-natal obesogenic diet, but with differential impacts on glucose-insulin adaptations during fasting in lambs. Acta Physiologica (Print), 210(1), 110-126. https://doi.org/10.1111/apha.12129 


\title{
Late gestation over- and undernutrition predispose for visceral adiposity in response to a post-natal obesogenic diet, but with differential impacts on glucose-insulin adaptations during fasting in lambs
}

\author{
P. Khanal, S. V. Husted, A. M. D. Axel, L. Johnsen, K. L. Pedersen, M. S. Mortensen, A. H. \\ Kongsted and M. O. Nielsen \\ Department of Veterinary Clinical and Animal Sciences, Faculty of Health and Medical Sciences, University of Copenhagen, \\ Frederiksberg, Denmark
}

Received 20 December 2012, revision requested 15 February 2013

revision received 30 May 2013, accepted 3 June 2013

Correspondence: M. O. Nielsen, Department of Veterinary Clinical and Animal Sciences, Faculty of Health and Medical Sciences, University of Copenhagen, Grønnegårdsvej 3, Ist Floor, DK-1870 Frederiksberg C, Denmark. E-mail: mette.olaf.nielsen@sund.ku.dk

\begin{abstract}
Aim: To investigate if late gestation under- or overnutrition has similar adverse impacts on visceral adiposity, metabolic and endocrine function in sheep, and if subsequent exposure to a high-fat diet in early post-natal life exaggerates the prenatal programming outcomes later in life.

Methods: Thirty-six twin-pregnant ewes were fed a NORM (fulfilling $100 \%$ of daily requirements for energy and protein), LOW (50\% of NORM) or HIGH diet (150\% of energy and $110 \%$ of protein requirements) during the last 6 weeks of gestation (term $=147$ days). Post-natally, the twin lambs were subjected to a high-fat or a moderate diet until 6 months of age (around puberty), where metabolic and endocrine adaptability to fasting was examined, and subgroups of animals were killed.

Results: Animals exposed to either prenatal under- or overnutrition had reduced subcutaneous fat deposition when fed a high-fat diet, resulting in higher ratios of mesenteric and peri-renal fat relative to subcutaneous fat compared to controls. This was not related to prenatal influences on plasma glucose or insulin. Irrespective of the prenatal diet, high-fat-fed lambs underwent changes resembling the metabolic syndrome with higher plasma glucose, cholesterol, non-esterified fatty acids, triglyceride and lactate combined with abdominal obesity. Peri-renal fat appeared to be a particular target of a high-fat diet post-natally.

Conclusion: Both prenatal under- and overnutrition predisposed for abdominal adiposity, apparently by reducing the expandability of subcutaneous adipose tissue and induced differential physiological adaptations to fasting. This study does not suggest that exposure to gestational overnutrition will provide a protective effect against development of hyperglycaemia later in life.

Keywords fat deposition, foetal malnutrition, metabolic profiles, obesity, post-natal overnutrition.
\end{abstract}

It has been known for many years that foetal undernutrition can lead to permanent and irreversible changes in body composition, metabolism and endocrine function, thus increasing the risks of metabolic disorders later in life (Hales \& Barker 1992, Ravelli et al. 1999, Godfrey \& Barker 2000). In recent years, mounting evidence has suggested that maternal overnutrition can have similar long-term adverse effects on the offspring (Muhlhausler et al. 2006, Grattan 2008, Ford \& Long 2011). Previous studies have revealed a 
' $U$ ' - shaped curve relating birth weight to the risk of adult obesity (Curhan et al. 1996, Godfrey \& Barker 2000, Dyer \& Rosenfeld 2011). This suggests that widely different nutritional insults (over- vs. undernutrition) during gestation, resulting in individuals being born at the extremes of the birth weight spectrum, may predispose for similar adverse outcomes on health and disease later in life. However, it is not known, whether these widely different nutritional insults, that is, over- or undernutrition in foetal life are affecting development of organs and body functions through similar physiological mechanisms. It is well recognized that nutrition during early post-natal life may also play an important role in determining the growth trajectory and post-natal obesity risk, and the immediate post-natal period has also been suggested as a period where long-term programming of health and disease can be induced (Patel \& Srinivasan 2011). It has been reported in several studies that exposure to overnutrition with an energy dense, highfat diet during early post-natal life increases the risk of metabolic syndrome later in life, particularly in offspring subjected to prenatal nutrient restriction, which might be due to an altered metabolic capacity to tolerate energy-rich diets or rapid catch-up growth in postnatal life (Guilloteau et al. 2009). However, it is not well known, whether such a worse-case scenario of mismatching pre- and post-natal exposures also applies for those individuals, who have been exposed to overnutrition during both foetal and early postnatal life. This question is important to elucidate in order to be able to establish efficient strategies for intervention in the future for individuals exposed to different kinds of foetal malnutrition.

Late gestation is the period, which contributes most to determine the birth weight in humans, and it has previously been reported that the majority of adipose tissue deposition occurs during late gestation in species born precocial, such as humans and sheep (Symonds \& Lomax 1992). We have developed the Copenhagen sheep model in order to be able to investigate the long-term consequences of malnutrition in a stage of gestation corresponding to the human third trimester (Nielsen et al. 2012), which are not possible to study in rodent or pig models, as these animal species are born altricial. In our sheep model, we have shown that late gestation undernutrition increases the risk of abdominal obesity upon exposure to an energy dense, high-fat diet during early post-natal life, possibly due to a reduced expandability of subcutaneous adipose tissue. Other sheep model studies have demonstrated similar outcomes in response also to early and midgestation undernutrition (Ford et al. 2007).

Recent studies indicate that maternal overnutrition may also have long-term adverse effects on adiposity in sheep offspring (Ford \& Long 2011), and such increased adiposity in offspring during early post-natal life has been associated with higher blood glucose levels (Muhlhausler et al. 2006).

In the present study, we aimed to test the hypothesis, using the Copenhagen sheep model, that both late gestation under- and overnutrition programme adipose tissue development to predispose for development of visceral adiposity later in life, based on induction of similar changes in metabolic adaptability to variations in nutrient supply, but despite similarities, individuals with a foetal history of overnutrition will have a superior ability to cope with a high-fat diet in early postnatal life.

\section{Materials and methods}

The present experiment was conducted at the experimental facilities on the farm Rosenlund, Lynge, Denmark under the auspices of the Faculty of Health and Medical Sciences, University of Copenhagen, Frederiksberg, Denmark. All experimental procedures were approved by the National Committee on Animal Experimentation, Denmark.

\section{Experimental animals and design}

The experiment was a $3 \times 2$ factorial design with three prenatal and two post-natal nutrition exposures, as illustrated in Figure 1. Thirty-six twin-pregnant multiparous (parities ranging from 3 to 5) cross-bred Texel ewes and their offspring were used in the experiment. During late gestation (last 6 weeks of pregnancy; term $=147$ days), the ewes were allocated to one of three different dietary regimens: NORM $(N=9)$ fulfilling daily requirements for energy and protein according to Danish feeding standards; LOW $(N=14)$ providing only $50 \%$ of energy and protein requirements; or $\mathrm{HIGH}(N=13)$ designed to provide $150 \%$ of energy and $110 \%$ of protein requirements. The ewes were allocated to these treatments 6 weeks prior to expected parturition, and it was attempted to reach as even a distribution of body weight and body condition score (BCS) across treatment groups as possible at the entry into the experiment (Table 1). It was ensured that all newborn lambs received colostrum within $3 \mathrm{~h}$ after birth. The lambs suckled their dam at will until 3 days after parturition, and then the dam was removed from her offspring. From 3 days to 6 months of age, one lamb from each twin pair received a high-carbohydrate-high-fat (HCHF) and the other lamb a moderate, conventional (CONV) diet. Allocation of the twin lambs to their respective post-natal dietary treatment groups was made right after birth using gender (first priority) and birth 


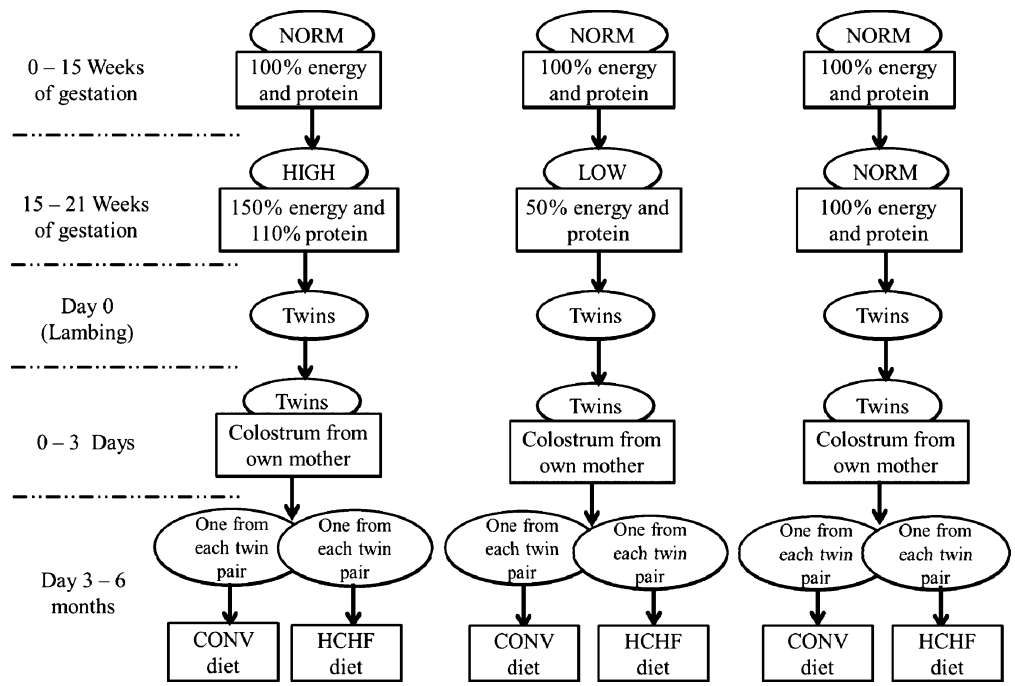

Figure I Schematic presentation of the experimental $3 \times 2$ factorial design. During the last 6 weeks of pregnancy, the pregnant ewes were given either a HIGH $(N=13 ; 150 \%$ of daily requirements for digestible energy and $110 \%$ of daily requirements for protein, respectively) or LOW $(N=14 ; 50 \%$ of requirements for energy and protein) or NORM diet $(N=9 ; 100 \%$ of requirements for energy and protein). After birth, one twin lamb was assigned to a HCHF ( $N=35 ; 18$ males; 17 females; high-carbohydrate high-fat diet consisting of a cream-milk replacer mix in a $1: 1$ ratio supplemented with rolled maize) or CONV $(N=35 ; 16$ males, 19 females; conventional diet consisting of milk replacer and hay until 8 weeks and hay only thereafter and adjusted to achieve moderate and constant growth rates of approx. $225 \mathrm{~g} \mathrm{day}^{-1}$ ). The twin lambs were assigned to their respective post-natal treatment groups right after birth ensuring as uniform a distribution of gender (first priority) and birth weight (second priority) as possible in the two post-natal feeding groups derived from a given prenatal treatment. The experimental design thus gave rise to six treatment groups: $\mathrm{HIGH}-\mathrm{CONV}(\mathrm{N}=13)$, five males, eight females; HIGH-HCHF $(N=13)$, five males, eight females; LOW-CONV $(N=13)$, six males, seven females; LOW-HCHF $(N=13)$, seven males, six females; NORM-CONV $(N=9)$, five males, four females; NORM-HCHF $(N=9)$, six males, three females.

Table I Daily energy and protein intake of twin-pregnant sheep during the last 6 weeks of gestation (term $=147$ days), and gender distribution and birth weights of their offspring

\begin{tabular}{lccc}
\hline & \multicolumn{2}{l}{ Pre-partum feeding levels (ewe) } & LOW \\
\cline { 2 - 4 } Parameters & HIGH & NORM & 14 \\
\hline No. of twin-pregnant ewes & 13 & 9 & $75.1 \pm 1.5$ \\
Weight of ewes 6 weeks pre-partum, kg & $76.3 \pm 1.5$ & $77.6 \pm 1.9$ & $3.64 \pm 0.10$ \\
BCS of ewes 6 weeks pre-partum & $3.87 \pm 0.10$ & $3.69 \pm 0.12$ & $79.4 \pm 1.4^{\mathrm{b}}$ \\
Weight of ewes just prior to partum, kg & $92.5 \pm 2.1^{\mathrm{a}}$ & $89.7 \pm 3.15^{\mathrm{a}}$ & $2.79 \pm 0.12^{\mathrm{c}}$ \\
BCS of ewes just prior to partum & $4.31 \pm 0.06^{\mathrm{a}}$ & $3.75 \pm 0.06^{\mathrm{b}}$ & $11.0 \pm 0.6^{\mathrm{c}}$ \\
DE, MJ day ${ }^{-1}$ (average for the & $34.8 \pm 0.6^{\mathrm{a}}$ & $22.9 \pm 0.8^{\mathrm{b}}$ & $125 \pm 4.6^{\mathrm{c}}$ \\
last 6 weeks pre-partum) & & & $263 \pm 5.7^{\mathrm{b}}$ \\
DCP intake, g day ${ }^{-1}$ (average for the & $284 \pm 4.5^{\mathrm{a}}$ & 18 & 28 \\
last 6 weeks pre-partum) & 26 & $11 / 7$ & $15 / 13$ \\
No. of lambs & $10 / 16$ & $4.35 \pm 0.18^{\mathrm{a}}$ & $3.89 \pm 0.15^{\mathrm{b}}$ \\
No. of each gender (M/F) & $4.38 \pm 0.15^{\mathrm{a}}$ & $3.56-5.05$ & $2.05-5.41$ \\
Birth weight, kg & $2.98-5.83$ & & \\
Range in birth weight, kg & & & \\
\hline
\end{tabular}

NORM, normal diet fulfilling requirements for energy and protein; HIGH, $150 \%$ of normal requirements for energy and $110 \%$ of normal requirements for protein; LOW, $50 \%$ of normal requirements for energy and protein; BCS, body condition score, scale from 1 to 5 (very lean to very fat); DE, digestible energy; DCP, digestible crude protein; M, male; F, female.

Data are presented as least square means \pm SEM. Data presented within rows with different superscript letters are significantly different at $P<0.05$. The DE intake increased from 6 weeks pre-partum to just prior to partum from 20.8 to $39.4,17.8$ to 24.3 and 8.70 to $11.7 \mathrm{MJ} \mathrm{day}^{-1}$ for HIGH, NORM and LOW ewes respectively. The increase in DCP from 6 weeks prepartum to just prior to partum were 199-311, 204-278 and 99.7-134 g day ${ }^{-1}$ for HIGH, NORM and LOW ewes respectively. 
weight (second priority) as allocation criteria to achieve as even a sex and birth weight distribution as possible across the two post-natal treatment groups within each prenatal treatment. In the following sections, HIGH, LOW and NORM will refer to prenatal nutrition exposures, and $\mathrm{HCHF}$ and $\mathrm{CONV}$ denote post-natal dietary treatments.

\section{Experimental housing and feeding of ewes}

All ewes were transferred to the experimental facility 1 week before initiation of the experiment for adaptation to the indoor experimental conditions and were given a subcutaneous bolus injection with vitamins (10 mL ADEsan and $10 \mathrm{~mL}$ Becomplex SC; Boehringer Ingelheim, Copenhagen, Denmark). The ewes were housed in individual bar-walled pens $(1.5 \times 1.5 \mathrm{~m})$ with sawdust as bedding material.

The diet for NORM-fed sheep consisted of artificially dried green hay (DanGrønt Speciality Feeds; DLG, Ølgod, Denmark) and commercial concentrate (Fårefoder F; Nordsjællands Andels Grovvareforening, Helsinge, Denmark) to fulfil $100 \%$ of the daily requirements for metabolizable energy (ME) and crude protein (NRC 2007). LOW sheep received $50 \%$ of the amount of hay and concentrate amounts fed to NORM-fed sheep on a metabolic body weight (MBW) basis. HIGH sheep were fed the same amount of hay and concentrate on a MBW basis as LOW sheep, but were supplemented with whole barley to provide $150 \%$ of $\mathrm{ME}$ and $110 \%$ of daily protein requirements. The average digestible energy and crude protein intakes during the last 6 weeks of gestation are given in Table 1. The LOW ewes were offered small amounts of barley straw (insignificant contribution to energy and protein intake) to avoid discomfort from sensation of hunger. All ewes were fed twice daily, one-half of the rations being given at each meal, and they had access to fresh drinking water ad libi- tum, and received a vitamin-mineral mix (Får Min; VILOMIX, Mørke, Denmark) to fulfil requirements (NRC 2007). During the first 3 days after parturition, all ewes were fed with hay ad libitum and supplemented with $300 \mathrm{~g}$ of concentrate and $300 \mathrm{~g}$ barley per day (in two daily meals) to ensure sufficient colostrum production for the offspring.

\section{Experimental housing and feeding of lambs}

Three days after parturition, the ewes were separated from their lambs, and the pens were subdivided into two smaller pens $(1.5 \times 0.75 \mathrm{~m})$ with sawdust as bedding material for individual housing and feeding of lambs. When the lambs reached the age of 2 months, they were transferred to larger pens $(1.5 \times 1.5 \mathrm{~m})$, where they were housed for the remainder of the experimental period.

The chemical composition of feedstuffs provided to lambs is given in Table 2. From 3 days till 8 weeks of age (milk-feeding period), CONV lambs were fed milk replacer (180 g milk powder $\mathrm{L}^{-1}$; Elitemilk Lamb, Vilofarm; DLA Group, Galten, Denmark) from a suckling bucket, and in addition to that they received a good quality hay from the age of 14 days. From 3 to 7 days of age, the lambs were fed four times a day and twice daily thereafter. Daily allowances of milk and hay were adjusted on a weekly basis to achieve daily moderate live weight gains of approx. $225 \mathrm{~g} \mathrm{day}^{-1}$.

The HCHF lambs were fed a mixture of $50 \%$ of the milk replacer and $50 \%$ dairy cream (Osted Ost og Mejeri ApS, Lejre, Denmark) ad libitum (until they reached the daily maximum of $2.5 \mathrm{~L} \mathrm{day}^{-1}$ ) until the end of the experimental feeding period (6 month). Rolled maize (Maize flakes; R2 Feed Partner A/S, Hedensted, Denmark) was fed ad libitum (until they reached the maximum allowance of $\left.1 \mathrm{~kg} \mathrm{day}^{-1}\right)$. The milk replacer-dairy cream mix was bottle-fed four

Table 2 Chemical composition and energy content of experimental feeds

\begin{tabular}{lllllllll}
\hline Feeds & $\begin{array}{l}\text { DM } \\
(\%)\end{array}$ & $\begin{array}{l}\text { Ash } \\
(\% \text { of DM })\end{array}$ & $\begin{array}{l}\text { aNDF } \\
(\% \text { of DM })\end{array}$ & $\begin{array}{l}\text { ADF } \\
(\% \text { of DM })\end{array}$ & $\begin{array}{l}\text { ADL } \\
(\% \text { of DM })\end{array}$ & $\begin{array}{l}\text { CP } \\
(\% \text { of DM })\end{array}$ & $\begin{array}{l}\text { Cfat } \\
(\% \text { of DM })\end{array}$ & $\begin{array}{l}\text { DE } \\
(\mathrm{MJ} \mathrm{kg} \mathrm{DM})\end{array}$ \\
\hline $\begin{array}{l}\text { Sheep diet } \\
\quad \text { Hay }\end{array}$ & 91.4 & 5.6 & 47.7 & 27 & 3.1 & 20.8 & 4.8 & 13.7 \\
$\quad \begin{array}{l}\text { Barley } \\
\text { Concentrate }\end{array}$ & 89.0 & 2.3 & 14 & 6 & 1.1 & 12.5 & 3.1 & 17.1 \\
Lamb diet & 87.7 & 7.7 & 25.8 & 18 & 2.8 & 15.3 & 3.8 & 12.8 \\
Hay & 93.1 & 6.8 & 50.4 & 32.3 & 3.5 & 19.1 & 3.7 & 13.5 \\
Maize & 89.5 & 0.6 & 4.1 & $<5$ & 0.9 & 8.5 & 1.9 & 16.3 \\
$\quad \begin{array}{l}\text { Milk powder } \\
\text { Cream }\end{array}$ & 95.6 & 7.1 & - & - & - & 22.5 & 23.6 & 19.2 \\
\hline
\end{tabular}

DM, dry matter; aNDF, amylase-treated neutral detergent fibre; ADF, acid detergent fibre; ADL, acid detergent lignin; CP, crude protein; Cfat, crude fat; DE, digestible energy. 
times daily during day 3-7 post-partum and twice daily thereafter from a suckling bucket. The digestible energy and protein intake of different lamb groups from 3 days to 6 months of age are provided in Table 3. Both lamb groups were supplemented daily with small amounts of barley straw (negligible contribution to energy and protein intake). Water was available ad libitum at all times and vitamin-mineral mix was provided based on requirements (NRC 2007).

All ewes gave birth to two live lambs. Two lambs died within the first 2 weeks after birth: one LOWHCHF male due to infectious peri-carditis, and one LOW-CONV male for unknown reasons (without showing any prior symptoms of illness). Thus, 72 lambs were included in registrations and samplings from birth until 1 week of age, and 70 lambs were included in registrations thereafter. At 4 weeks of age, one $\mathrm{HIGH}-$ CONV and one LOW-CONV lamb developed symptoms of pneumonia and were treated with antibiotics (Curamox ${ }^{\mathrm{R}}$ Vet., $150 \mathrm{mg} \mathrm{mL}^{-1}$; Boehringer Ingelheim) for 3 days, whereafter they fully recovered. One HIGHCONV lamb was successfully treated for diarrhoea (Baycox Sheep vet., Bayer HealthCare, Leverkusen, Germany) at the age of 14 weeks.

For twin-pregnant ewes, feed intake was recorded over a 24-h period twice weekly, and body weights and BCS were recorded once a week. The lambs were examined and weighed immediately after birth. Lamb body weights were recorded weekly until 6 months of age. Body proportions [crown-rump length, girth circumference, height over withers, head width (using slide gauge from eye to eye)] were measured at day 1 , and at 3 and 6 months of age. Feed intakes were recorded daily during the first week of life and once weekly over a 24 -h period thereafter.

\section{Blood samplings}

Blood samples were collected from all ewes at approx. 11:00 AM by jugular venipuncture once on weeks -7 , $-5,-3$ and -1 week prior to expected parturition, and on the day after lambing. Additionally, blood samples from lambs were collected the day after birth (day 1) by jugular venipuncture at approx. 11:00 AM.

At 6 months of age, the lambs were subjected to a 44-h fasting period. They had free access to drinking water during that time. Catheters (INTRAFLON 2, $2.7 \mathrm{~mm}$; Laboratories Pharmaceutiques, VYGON, Écouen, France) were inserted into both jugular veins at least 1 day prior to initiation of the fasting period to facilitate repeated collection of blood samples as described by Husted et al. (2007). The first sample was taken prior to removal of the food (zero sample, at approx. 13:00 PM) and thereafter at times 24 (at approx. 13:00 PM) and $44 \mathrm{~h}$ (at approx. 09:00 AM) after onset of the fasting period.

All blood samples were collected in EDTA-coated tubes and immediately placed on ice until centrifugation at $1800 \mathrm{~g}$ for $15 \mathrm{~min}$ at $4{ }^{\circ} \mathrm{C}$. Plasma was transferred to cryo-vials and stored at $-20{ }^{\circ} \mathrm{C}$ for later analysis.

\section{Laboratory analyses}

Glucose, insulin, non-esterified fatty acids (NEFA), triglycerides (TG), blood urea nitrogen (BUN), creatinine, lactate, $\beta$-hydroxy butyrate (BOHB), $\gamma$-glutamyltrans-

Table 3 Digestible energy and protein intakes of experimental lambs from 3 days to 6 months of age

\begin{tabular}{lcccccc}
\hline Parameters & NORM-CONV & NORM-HCHF & HIGH-CONV & HIGH-HCHF & LOW-CONV & LOW-HCHF \\
\hline $\begin{array}{l}\text { Number of lambs (M/F) } \\
\left.\text { DE intake (MJ day }{ }^{-1}\right)\end{array}$ & $5 / 4$ & $6 / 3$ & $5 / 8$ & $5 / 8$ & $6 / 7$ & $7 / 6$ \\
$\quad$ 3 days-8 weeks & $4.5 \pm 0.5^{\mathrm{b}}$ & $8.4 \pm 0.5^{\mathrm{a}}$ & $4.3 \pm 0.4^{\mathrm{b}}$ & $8.0 \pm 0.4^{\mathrm{a}}$ & $4.3 \pm 0.4^{\mathrm{b}}$ & $7.7 \pm 0.4^{\mathrm{a}}$ \\
$\quad$ 8 weeks-6 months & $11.9 \pm 0.9$ & $12.5 \pm 0.9$ & $12.4 \pm 0.7$ & $11.5 \pm 0.7$ & $11.7 \pm 0.7$ & $10.9 \pm 0.7$ \\
DCP (g day $^{-1}$ ) & & & & & \\
$\quad$ days-8 weeks & $42.9 \pm 1.6^{\mathrm{a}}$ & $18.1 \pm 1.6^{\mathrm{b}}$ & $41.2 \pm 1.3^{\mathrm{a}}$ & $17.2 \pm 1.3^{\mathrm{b}}$ & $40.5 \pm 1.3^{\mathrm{a}}$ & $17.2 \pm 1.3^{\mathrm{b}}$ \\
$\quad$ 8 weeks-6 months & $122 \pm 8.6^{\mathrm{a}}$ & $29.8 \pm 8.6^{\mathrm{b}}$ & $129 \pm 7.1^{\mathrm{a}}$ & $27.2 \pm 7.1^{\mathrm{b}}$ & $120 \pm 7.1^{\mathrm{a}}$ & $26.7 \pm 7.2^{\mathrm{b}}$ \\
\hline
\end{tabular}

NORM, HIGH, LOW, see legends to Table 1; HCHF, high-carbohydrate high-fat diet; CONV, conventional diet to achieve moderate and constant growth rates of approx. $225 \mathrm{~g} \mathrm{day}^{-1}$; M, male; F, female; DE, digestible energy; DCP, digestible crude protein.

Data are presented as least square means \pm SEM and within rows data with different superscript letters are significantly different at $P<0.05$. The experimental lambs were offspring of NORM or HIGH or LOW ewes during the last 6 weeks of gestation. From 3 days to 6 months of age, lambs were fed either the HCHF or the CONV diet. The HCHF diet included rolled maize and dairy cream-milk replacer mix. The CONV diet consisted of hay and milk replacer until 8 weeks of age and hay only thereafter. The HCHF lambs had significantly higher intake of energy and lower intake of protein until 8 weeks as compared to CONV lambs $(P<0.0001)$. From 8 weeks to 6 months, CONV lambs had significantly higher intake of protein compared to HCHF lambs $(P<0.0001)$. 
ferase (GGT) and cholesterol levels were determined in plasma samples obtained from ewes and all lambs at the University of Copenhagen, Frederiksberg, Denmark as previously described (Kongsted et al. 2013). The intra- and interassay coefficients of variation $(\mathrm{CV})$ were below 5 and $10 \%$, respectively for all assays.

Analyses for leptin, IGF-1, cortisol and ghrelin were performed at The University of Western Australia, Perth, Australia. Plasma leptin was measured in duplicate by a double-antibody radio-immunoassay (Blache et al. 2000). Plasma IGF-1 was assayed in duplicate by a double-antibody radio-immunoassay using human recombinant IGF-1 (30-A 188; Fitzgerald Industries, Concord, MA, USA) and antihuman IGF-1 antiserum (AFP4892898; National Hormone and Pituitary Program of the National Institute of Diabetes and Digestive and Kidney Disease, Torrance, CA, USA) following an acid-ethanol extraction and cryo-precipitation (Breier et al. 1991). Plasma cortisol levels were determined using a commercial radioimmunoassay kit (Clinical AssaysTM, GammaCoatTM, cortisol 125I RIA Kit; DiaSorin, Stillwater, MN, USA; Beausoleil et al. 2008). Plasma ghrelin was measured in duplicate by a modified double-antibody RIA method based on the Linco total Ghrelin RIA kit (GHRT-89HK; Linco, St Charles, MI, USA) as previously described by Miller et al. (2009). The samples were processed in a single assay for leptin, IGF-1 and ghrelin where intra-assay CVs were below $7 \%$, whereas plasma cortisol was analysed in two assays with intra- and inter-CVs of below 2 and 5\% respectively.

\section{Slaughtering of subgroups of experimental animals at 6 months of age}

Twenty-six lambs in total [NORM-CONV: 3 (3M, OF), NORM-HCHF: 3 (3M, OF), HIGH-CONV: 5 (2M, 3F), HIGH-HCHF: 5 (2M, 3F), LOW-CONV: 5 (2M, 3F), LOW-HCHF: 5 (3M, 2F)] were selected for slaughtering at 6 months of age. Only one lamb from each twin pair was selected for slaughtering allowing another lamb within each twin pair to continue in the experiment for later studies as adults. The subgroups of lambs were selected within each treatment group so that slaughtered and surviving animals (continuing in the experiment) had as uniform a distribution of body weight and gender as possible, except that we chose to slaughter only males from the NORMCONV and NORM-HCHF groups due to the smaller group size. This was done to allow a sufficient number of females to continue in the experiment to assess the long-term consequences of early life exposures in both genders, which will be published subsequently. Prior to slaughtering, body weight and body propor- tions were determined. Just before slaughtering, animals were anaesthetized with propofol (5-6 mg i.m. kg-1 body weight; B. Braun, Melsungen, Germany) and they were thereafter killed by decapitation. Immediately after decapitation, different organs were excised and weighed.

\section{Statistical analyses}

Statistical evaluation of all data was performed in SAS (v.9.2; SAS Institute, Inc., Cary, NC, USA). Homogeneity of variance was evaluated by visual inspection of residual plots and normality of residuals was tested by means of quantile-quantile plots. Log transformations were applied when it was needed to obtain normal distribution of residuals. The birth weights of lambs were analysed by the PROC GLIMMIX procedure, where ewe was included as random effect to account for the twin effect. Different organ and tissue weights were analysed using the PROC GLM procedure to compare effects of pre- and post-natal nutrition and lamb gender. The remaining data, including fasting challenge tests, were analysed as repeated measures by the PROC GLIMMIX procedure. For the repeated measurements, different correlation structures between measurements and inhomogeneous variances were tested, and the structure yielding the best fit was chosen. The model included fixed effects of feeding level, gender and time of sampling; individual sheep and lambs within feeding level were included as random effects, and samples within sheep and lambs were considered repeated measurements. Within the post-natal HCHF group, a few animals (one from the NORM, two from the HIGH and two from the LOW prenatal groups) had poorer growth rates compared to other animals in their groups, which was evident from 4 to 6 weeks of age, and they reached substantially lower body weights at 6 months of age (all $<30 \mathrm{~kg}$ ) and compared to all the rest of the HCHF-fed animals (all $>35 \mathrm{~kg}$ ), and they attained a characteristic skinny appearance not observed in any of the other animals irrespective of post-natal feeding, but despite the skinny appearance, they had extensive abdominal fat deposition as observed at slaughter. In the statistical analyses, we therefore also decided to test if these 'small-skinny-fat' animals, although few in number, showed any indications of being different from the rest of the animals within their group with 'normal' appearances and growth trajectories for the parameters studied, and the selection criteria was based on a body weight below $30 \mathrm{~kg}$. The model included fixed effects of phenotype, age of animal or time of sampling and phenotype ('small-skinny-fat' or 'normal'). Individual sheep and lambs were included as random effects, and parameters within sheep and lambs were 
treated as repeated measurements. Differences in least square means (LS means) were compared by Tukey's multiple comparison test, and presented results are expressed as LS means with standard error of mean (LS means \pm SEM). The level of significance was set at $P<0.05$.

\section{Results}

Unless it is specifically stated in the following, we did not for the studied parameters detect any significant effects of the prenatal nutrition, the interactions between pre- and post-natal diets, interactions with time (age of the animal during development or the time course of changes in metabolic and endocrine profiles during the fasting exposure), effects of gender or indications of differences between the 'smallskinny-fat' versus 'normal' HCHF lambs.

\section{Feed intake, body weight and BCS of pregnant sheep}

At the onset of the experiment (6 weeks pre-partum), all sheep had similar body weights and BCS (Table 1), but during the last 6 weeks of gestation, NORM and $\mathrm{HIGH}$ ewes increased their body weights more, and they obtained significantly higher body weights than LOW ewes during the last 2 weeks of gestation. In the last week of gestation, the BCS of the ewes reflected the feeding level, as HIGH ewes attained significantly higher BCS followed by NORM and then LOW ewes $(P<0.0001$; Table 1$)$.

\section{Metabolic responses in pregnant sheep}

The plasma metabolite levels were similar across treatment groups at the onset of the experiment. During the last 6 weeks of gestation, concentrations changed as would be expected based from fed intakes and gestational changes in the ewes, and HIGH ewes compared to NORM and LOW ewes increased plasma concentrations more of glucose $(3.70 \pm 0.12-4.5 \pm$ $0.10 \mathrm{~mm}$ in $\mathrm{HIGH} ; 3.52 \pm 0.16-4.15 \pm 0.10 \mathrm{~mm}$ in NORM, $P=0.0004$; and 3.70 $\pm 0.12-3.99 \pm 0.12 \mathrm{~mm}$ in LOW, $P<0.0001)$ and GGT $(48.3 \pm 3.1-55.5 \pm$ $3.2 \mathrm{U} \mathrm{L}^{-1}$ in $\mathrm{HIGH} ; 50.4 \pm 4.2-48.1 \pm 3.3 \mathrm{U} \mathrm{L}^{-1}$ in NORM, $P=0.02$; and $46.0 \pm 2.9-37.8 \pm 2.1 \mathrm{U} \mathrm{L}^{-1}$ in LOW, $P=0.002)$. The LOW ewes, however, increased their plasma levels of creatinine $(69.3 \pm 3.8$ $95.2 \pm 3.6 \mu \mathrm{mm})$ and NEFA $(0.27 \pm 0.07-0.66 \pm$ $0.05 \mathrm{~mm})$ more during late gestation compared to NORM ewes $(78.9 \pm 4.9-79.0 \pm 4.5 \mu \mathrm{mM}$ for creatinine and $0.34 \pm 0.09-0.30 \pm 0.07 \mathrm{mM}$ for NEFA; $P=0.05$ and $P=0.01$, respectively), and $\mathrm{HIGH}$ ewes $(82.8 \pm 3.9-76.6 \pm 3.7 \mu \mathrm{mm}$ for creatinine and $0.39 \pm 0.07-0.21 \pm 0.05 \mathrm{~mm}$ for NEFA; $P=0.009$ and $P<0.0001$ respectively). Overall, the NORM-fed ewes had higher TG $(0.44 \pm 0.02 \mathrm{~mm})$ and BUN $(8.9 \pm 0.30 \mathrm{mM})$ concentrations compared to $\mathrm{HIGH}$ $(0.29 \pm 0.02 \mathrm{~mm} \quad \mathrm{TG}$ and $7.5 \pm 0.25 \mathrm{~mm}$ BUN; $P<0.0001$ and $P=0.0007$, respectively) and LOW ewes $(0.32 \pm 0.02 \mathrm{~mm}$ TG and $6.7 \pm 0.24 \mathrm{~mm}$ BUN; $P=0.0001$ and $P<0.0001$, respectively), and BUN levels were in turn significantly higher in $\mathrm{HIGH}$ than in LOW ewes $(P<0.05)$.

\section{Birth weight and body proportions in lambs}

The prenatally undernourished LOW lambs had reduced birth weights compared to lambs born to HIGH $(P=0.009)$ and NORM dams $(P=0.03)$, whereas no significant difference was obtained in lamb birth weights from NORM and HIGH ewes (Table 1). $\mathrm{HIGH}$ and NORM lambs had similar growth patterns until 8 weeks of age and grew at a higher rate than LOW lambs (Fig. 2). After 8 weeks of age, the NORM lambs grew faster than both HIGH and LOW lambs resulting in a significant interaction between prenatal diet and animal age $(P=0.0004)$. The CONV lambs had significantly higher body weights than HCHF lambs from 4 to 8 (age of weaning for CONV lambs) weeks of age, but from week 10, HCHF lambs increased their body weight gain faster

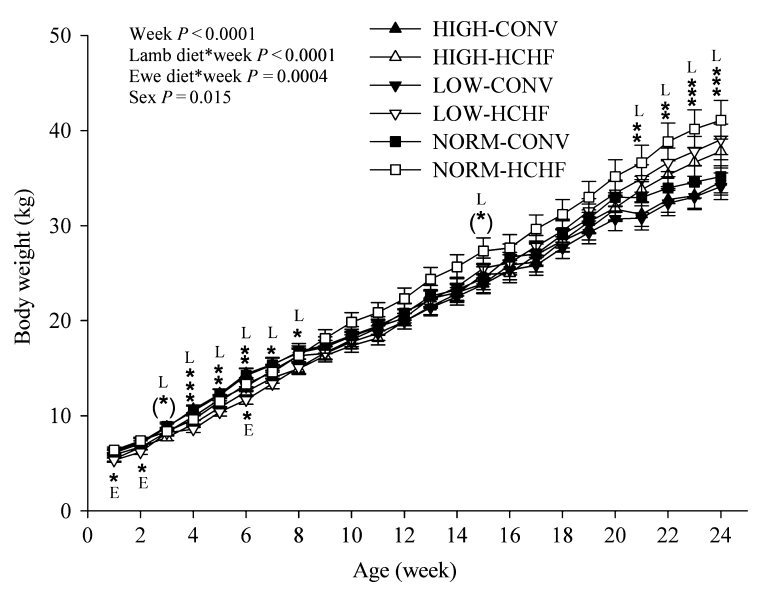

Figure 2 Changes in body weights of lambs from birth to 24 weeks (around puberty) of age. NORM; diet fulfilling daily requirements for energy and protein; HIGH, NORM, LOW, HCHF, CONV: see legends to Figure 1. From 4 to 8 weeks of age, CONV lambs had significantly higher body weights than HCHF lambs, but from week 21 and onwards, HCHF lambs became significantly heavier than CONV lambs. Values are least square (LS) means \pm SEM represented by vertical bars. Within week, LS means were significantly different at $\left(^{*}\right), P=0.05 ; * P<0.05 ; * P<0.01$; $* * * P<0.001$. 
than the CONV lambs, and from week 21 onwards HCHF lambs became significantly heavier than CONV lambs $(P<0.0001$ for the interaction between post-natal diet and age; Fig. 2). Within HCHF lambs, a few animals did not grow well from the beginning, and these 'small-skinny-fat' lambs by 24 weeks of age attained significantly lower body weights $(>30 \mathrm{~kg})$ compared to the rest of HCHF lambs $(>35 \mathrm{~kg}$; $P<0.001)$. Female lambs had lower body weights than male lambs, and this difference amounted to on average approx. $2 \mathrm{~kg}$ at 6 months of age $(P=0.015)$. The HCHF lambs in general attained higher girth circumference $(P=0.005)$ and head width $(P=0.012)$ compared to CONV lambs. Overall, male lambs had higher head circumference $(P<0.0001)$, height above wither $(P=0.017)$ and crown-rump length $(P<0.05)$ than female lambs.

\section{Dietary intakes by lambs}

There were no effects of gender or prenatal diet on the post-natal intakes of individual feeds over the time course of this experiment $(P>0.24$ for all parameters and interactions; data not shown). During the milkfeeding period (from day 3 to 8 weeks of age), digestible energy intakes were higher in the HCHF lambs than in the CONV lambs $(P<0.001$; Table 3$)$, for which feed intakes were adjusted weekly to achieve the same moderate and constant weight gain. However, protein intake was significantly lower in HCHF lambs compared to CONV lambs for the first 8 weeks of life. From 8 weeks (weaning of CONV lambs) to 6 months of age, the average daily intakes of digestible energy were in the same range for all experimental groups; however, protein intakes were markedly lower in HCHF (approx. 26.7-29.8 $\mathrm{g} \mathrm{day}^{-1}$ ) lambs compared to CONV lambs $\left(120-128 \mathrm{~g} \mathrm{day}^{-1} ; P<0.0001\right)$. The 'small-skinny-fat' HCHF lambs had lower daily average intakes of cream (714 vs. $1153 \mathrm{~mL}$ day $^{-1}$ ), daily digestible energy (7.01 vs. $\left.11.0 \mathrm{MJ} \mathrm{day}^{-1} ; P<0.0001\right)$ and digestible protein (16.1 vs. $\left.25.0 \mathrm{~g} \mathrm{day}^{-1} ; P<0.0001\right)$ compared with the other HCHF animals.

\section{Metabolic and endocrine adaptations during fasting}

Glucose. Plasma glucose levels were similar in CONV lambs irrespective of their prenatal diet $(P=0.0008)$, but in HCHF lambs, HIGH-HCHF lambs had higher blood glucose levels compared to LOW-HCHF lambs prior to fasting at time $0(P=0.0003)$ and $44 \mathrm{~h}$ after fasting $(P=0.024$; Fig. 3a). The HCHF lambs had substantially higher baseline plasma glucose levels compared to CONV lambs $(P<0.0001)$, but this difference decreased during fasting and after $44 \mathrm{~h}$ of fasting, glucose levels in HCHF lambs had dropped to levels only slightly higher than those observed in CONV lambs $(P<0.05)$.

Lactate. Baseline lactate levels were almost twice as high in $\mathrm{HCHF}$ lambs compared to CONV lambs $(P<0.01$; Fig. 3b). Plasma lactate level decreased as fasting progressed, but more in HCHF-fed animals compared to CONV animals and $44 \mathrm{~h}$ after fasting, lactate levels had decreased in HCHF lambs to similar levels as observed in CONV animals, that is, a pattern resembling that observed for glucose. The female lambs had higher lactate level than the male lambs $(P=0.004)$.

Non-esterified fatty acids. The HCHF lambs had more than fourfold basal NEFA levels than CONV lambs $(P<0.0001$; Fig. 3c). Plasma NEFA steadily increased throughout the fasting period, but much more pronounced in CONV lambs compared to $\mathrm{HCHF}$ lambs, and after $44 \mathrm{~h}$ of fasting, the NEFA levels were only slightly higher in HCHF compared to CONV lambs.

$\beta$-Hydroxy butyrate. The baseline BOHB level was more than twofold higher in CONV compared to HCHF lambs $(P<0.0001)$, but as fasting proceeded, BOHB levels in CONV lambs were more than halved, whereas plasma $\mathrm{BOHB}$ levels were increased by more than threefold in HCHF lambs, thus creating the opposite picture after $44 \mathrm{~h}$ of fasting $(P<0.0001$ for the interaction between post-natal diet and time; Fig. 3d).

Blood urea nitrogen. The baseline BUN was similar in CONV and HCHF lambs, but the BUN levels were increased much more in CONV lambs, and they attained higher BUN levels ( $>3$-fold) during fasting than HCHF lambs $(P<0.0001$; Fig. 3e).

Triglycerides. The HCHF lambs had more than twofold higher plasma TG levels compared to CONV lambs at all time points prior to and during fasting $(P<0.0001$; Fig. 3f $)$. As fasting proceeded, the TG level in HCHF lambs dropped sharply over the first $24 \mathrm{~h}$ and then stabilized at levels, which remained higher than in CONV lambs $(P=0.04$ for the interaction between post-natal diet and time).

Creatinine. The HCHF lambs $(104.43 \mu \mathrm{mm})$ had approx. $50 \%$ higher basal plasma creatinine level than CONV lambs $(70.68 \mu \mathrm{mm})$, and this difference was evident at all time points during fasting $(P<0.0001$; data not shown). Both HCHF and CONV lambs increased creatinine levels until $24 \mathrm{~h}$ after fasting followed by a small decrease in HCHF lambs 

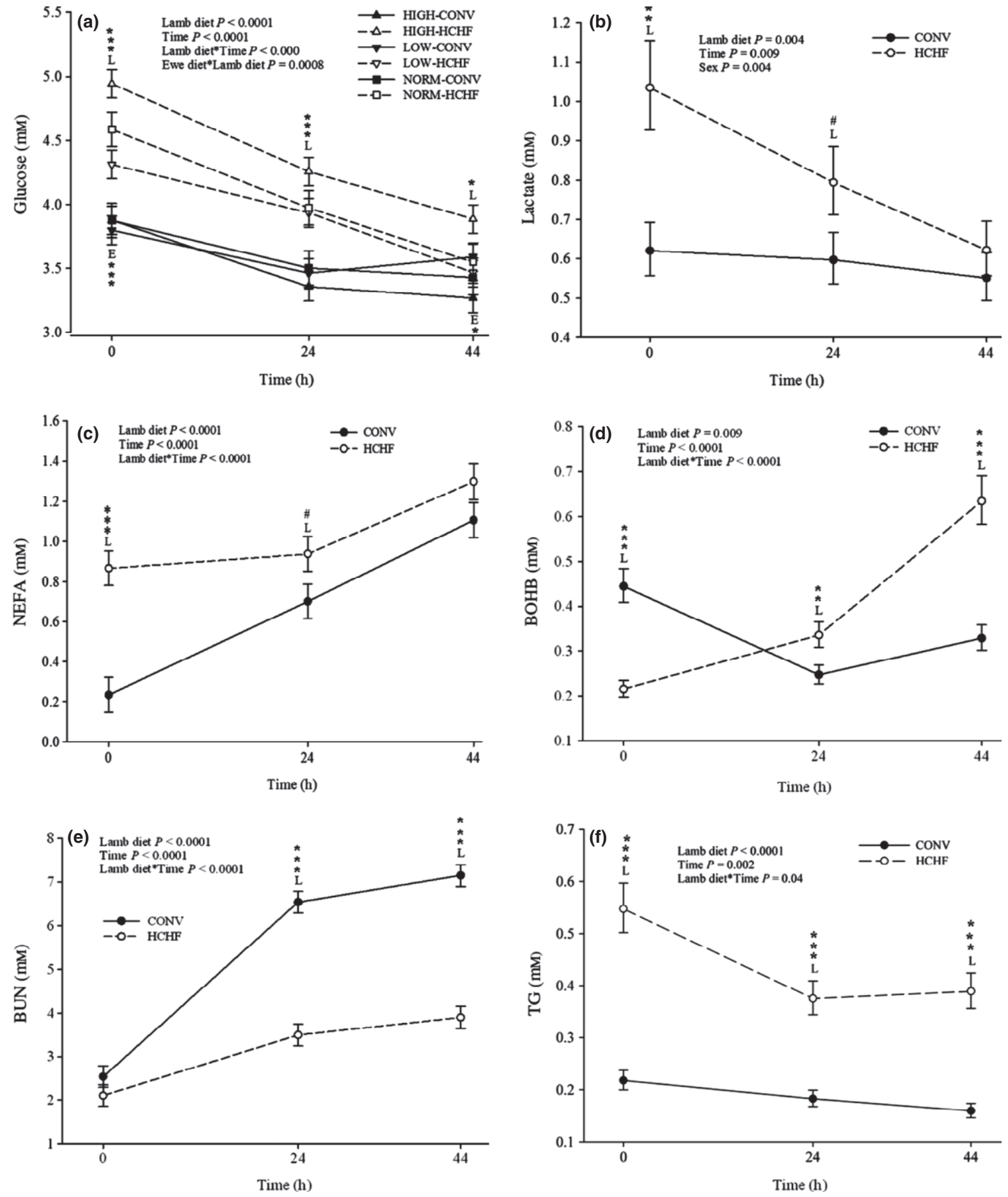

Figure 3 Changes in plasma levels during a 44-h fasting period of (a) glucose (b) lactate (c) non-esterified fatty acids (NEFA) (d) $\beta$-hydroxy butyrate (BOHB) (e) blood urea nitrogen (BUN), and (f) creatinine. HIGH, NORM, LOW, HCHF, CONV: see legends to Figure 1. E, ewe diet (prenatal) effect; L, lamb diet (post-natal) effect. Values are least square (LS) means \pm SEM represented by vertical bars. Within sampling hour, LS means were significantly different at $* P<0.05 ; * * P<0.01 ; * * * P<0.0001$.

( $P=0.0027$ for the interaction between post-natal diet and time). The small-skinny-fat HCHF lambs had lower creatinine levels compared to the rest of the HCHF lambs (87.9 vs. $115 \mu \mathrm{mm} ; P=0.004)$.
Cholesterol and GGT. Overall, GGT and cholesterol levels were significantly higher in the HCHF (161.70 $\mathrm{U} \mathrm{L}^{-1}$ and $4.31 \mathrm{~mm}$, respectively) compared to the CONV lambs $\left(61.70 \mathrm{U} \mathrm{L}^{-1}\right.$ and $1.60 \mathrm{~mm}$, 
respectively; $P<0.001$; data not shown), but levels were not affected by fasting or the prenatal diet.

\section{Endocrine responses during fasting}

Insulin. The baseline insulin concentrations were highest in the unfasted state and higher in the HCHF than CONV lambs $(P=0.0183$; Fig. 4a). Insulin levels decreased as fasting progressed. Within HIGH and NORM lambs, there were no effects of the post-natal diet, but LOW-CONV lambs maintained higher insulin levels throughout fasting and higher significantly higher than in LOW-HCHF lambs by the end of the 44-h fasting period $(P=0.014)$. CONV lambs in general had less pronounced reductions in insulin levels during fasting and maintained higher insulin levels at time points
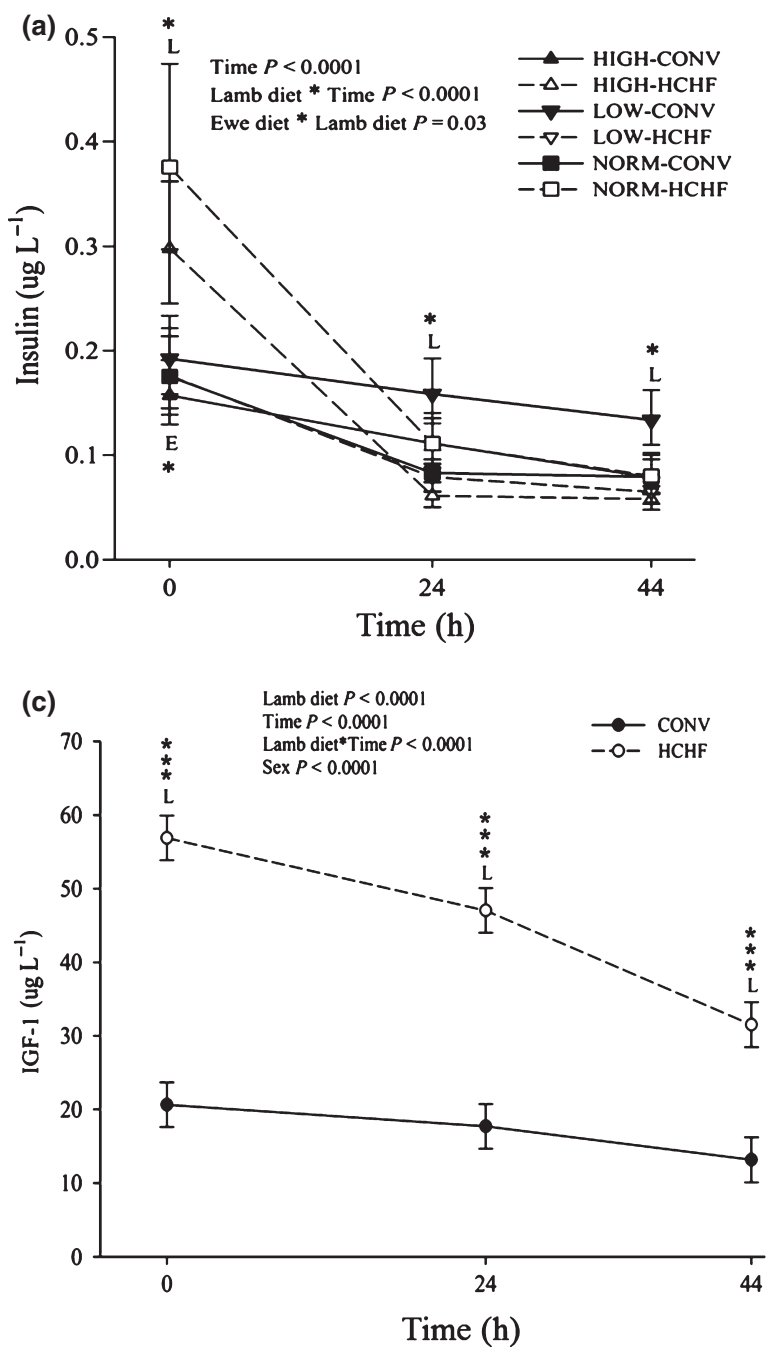

$24(P=0.0166)$ and $44 \mathrm{~h}(P=0.0229)$ compared to HCHF lambs. Glucose/insulin ratios were calculated as a measure of insulin sensitivity. There was no effect of the post-natal on this ratio within the HIGH and NORM lambs, but among the LOW lambs, the LOW-

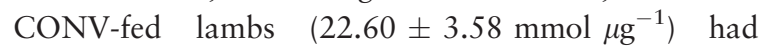
lower glucose/insulin ratio $(P=0.0056)$ as compared to the LOW-HCHF-fed lambs (40.59 $\pm 6.43 \mathrm{mmol} \mu \mathrm{g}^{-1}$; $P=0.0466$ for the interaction between the pre- and post-natal nutrition).

Leptin and IGF-1. The HCHF lambs had approximately twofold higher leptin and IGF-1 levels compared to CONV lambs at all time points during the pre-fasted and fasted states $(P<0.0001)$, and plasma leptin and IGF-1 levels decreased during fasting in a
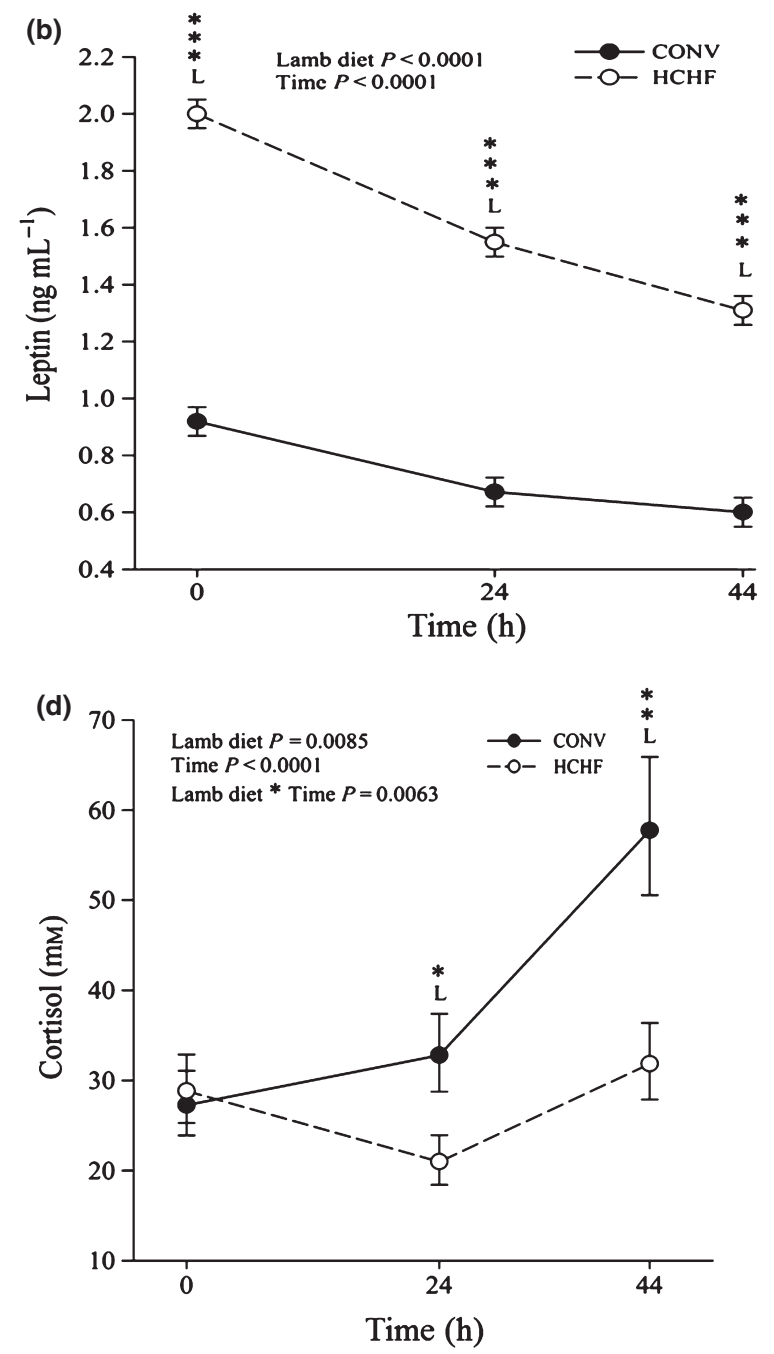

Figure 4 Changes in plasma levels during a 44-h fasting period of (a) insulin, (b) leptin, (c) insulin-like growth factor-1 (IGF-1) and (d) cortisol. HIGH ( $N=26$; ten male, 16 female); NORM ( $N=18 ; 11$ male, seven female); LOW $(N=26 ; 13$ male, 13 female); $\operatorname{HCHF}(N=35 ; 18$ male, 17 female) and $\operatorname{CONV}(N=35 ; 16$ male, 19 female): see legends to Figure 1 . E, ewe diet (prenatal) effect; L, lamb diet (post-natal) effect. Values are least square (LS) means \pm SEM represented by vertical bars. Within sampling hour, LS means were significantly different at $* P<0.05 ; * * P<0.01 ; * * P<0.0001$. 
similar fashion in all treatment groups irrespective of the pre- and post-natal diet (Fig. 4b,c). The 'smallskinny fat' lambs had lower levels of leptin (in the fed state: 1.26 vs. $1.76 \mathrm{ng} \mathrm{mL}^{-1} ; P=0.031$ ) and IGF-1 (in the fed state: 14.3 vs. $49.1 \mathrm{ng} \mathrm{mL}^{-1}, P=0.0071$; $24 \mathrm{~h}$ after fasting: 28.3 vs. $56.5 \mathrm{ng} \mathrm{mL}^{-1}, P=0.028$ ) compared to the rest of the HCHF lambs.

Cortisol. The baseline cortisol levels were similar in HCHF and CONV lambs (Fig. 4d). However, CONV lambs had more pronounced increases in cortisol levels during fasting $(P<0.05)$, whereas plasma cortisol was unaffected by fasting in HCHF animals.

Ghrelin. Plasma ghrelin levels were not affected by neither pre- or post-natal nutrition, and they in general increased during the first $24 \mathrm{~h}$ of fasting and normalized again thereafter in all groups $(P<0.0029$; data not shown).

\section{Fat-deposition patterns and organ weights}

Fat deposition. The subcutaneous fat deposition was significantly higher in NORM lambs compared to $\mathrm{HIGH}$ lambs both expressed as absolute weights and when expressed relative to body weight $(P=0.01$ and $P=0.02$, respectively), whereas there were no significant differences between HIGH and LOW lambs or NORM and LOW, although LOW had numerically lower values for subcutaneous fat weights than HIGH (Table 4). The impact of the prenatal diet could be ascribed solely to the animals that had been exposed to a post-natal obesogenic diet, which resulted in an almost significant interaction of pre- and post-natal $\operatorname{diet}(P=0.0595)$. The NORM-HCHF lambs had significantly higher subcutaneous fat deposition than HIGH-HCHF $(P<0.0001)$. There were no significant influences of the prenatal nutrition on deposition of neither mesenteric, peri-renal nor sternal fat.

The HCHF lambs had significantly higher depositions in absolute weights of subcutaneous (approx. 5.5-fold), mesenteric (approximately fivefold), perirenal (approximately ninefold) and sternal (approx. 4.6-fold) fat than CONV lambs, and this picture was also seen after correction for body weight $(P<0.0001$, for all fat depots; Table 4). The HCHF female lambs had significantly higher bodyweight-corrected perirenal fat deposition than the HCHF male lambs $(P=0.0025)$, but a gender effect was not observed in CONV lambs. There were no gender effects for any of the other fat depots, when correcting for differences in body weight.

Fat-deposition pattern. The prenatal diet influenced the preference for fat deposition in the subcutaneous area compared to the abdominal region. The NORM lambs $(0.33 \pm 0.04)$ increased subcutaneous fat: mesenteric fat ratios compared to both $\mathrm{HIGH}(0.22 \pm 0.03$, $P=0.018)$ and LOW lambs $(0.22 \pm 0.03, P=0.02$; Fig. 5a). Similarly, the NORM lambs $(0.34 \pm 0.03)$ had significantly higher ratios of subcutaneous to perirenal fat as compared to both HIGH $(0.23 \pm 0.02$, $P=0.009)$ and LOW lambs $(0.22 \pm 0.02, P=0.005$; Fig. $5 \mathrm{c})$. The prenatal diet did not have any significant effect on the distribution of fat within the abdomen, that is, between the mesenteric and peri-renal depots (Fig. 5e).

The post-natal diet did not have any significant effect on the relative distribution of fat between the subcutaneous and mesenteric region (Fig. 5b). However, the HCHF diet induced increased deposition of peri-renal fat relative to deposition of fat in both the subcutaneous and mesenteric regions, as reflected by significantly lower ratios of subcutaneous to peri-renal fat in HCHF lambs $(0.19 \pm 0.02)$ compared to CONV lambs $(0.34 \pm 0.02 ; P<0.0001$; Fig. $5 \mathrm{~d})$, and reduced mesenteric to peri-renal fat ratio in $\mathrm{HCHF}$ lambs $(0.74 \pm 0.07)$ compared to $\mathrm{CONV}$ lambs $(1.39 \pm 0.07 ; P<0.0001$; Fig. 5f).

Other organ and tissue weights. The prenatal nutrition exposure had no significant impact on gross or bodyweight-corrected weights of any of the other organs or tissues studied, except for the thyroids. The NORM and LOW lambs had significantly higher gross thyroid weights than HIGH lambs $(P<0.05)$.

The HCHF-fed lambs has significantly higher gross weights of thyroids $(P=0.0005)$, liver $(P<0.0001)$, heart $(P<0.0001)$, longissimus dorsii $(P<0.0003)$ and biceps femoris $(P=0.02)$ compared to lambs fed the CONV diet. In fact, liver weight was approximately doubled in HCHF compared to CONV lambs, and except for the skeletal muscles longissimus dorsii and biceps femoris, the post-natal diet effects persisted after correction for body weight. In contrast to the other organs and tissues, kidney weights, both gross and as a proportion of body weight, were found to be significantly reduced in lambs fed the HCHF as compared to CONV diet $(P<0.002$; Table 4$)$. The male lambs had significantly higher gross kidney and heart weights than female lambs $(P<0.03)$, but these gender effects disappeared upon correction for body weight (Table 4). Female lambs had significantly higher weight of biceps femoris compared to male lambs, but only when expressed relative to body weight $(P<0.05)$.

\section{Discussion}

We aimed to evaluate whether maternal malnutrition in the form of over- or undernutrition would have 


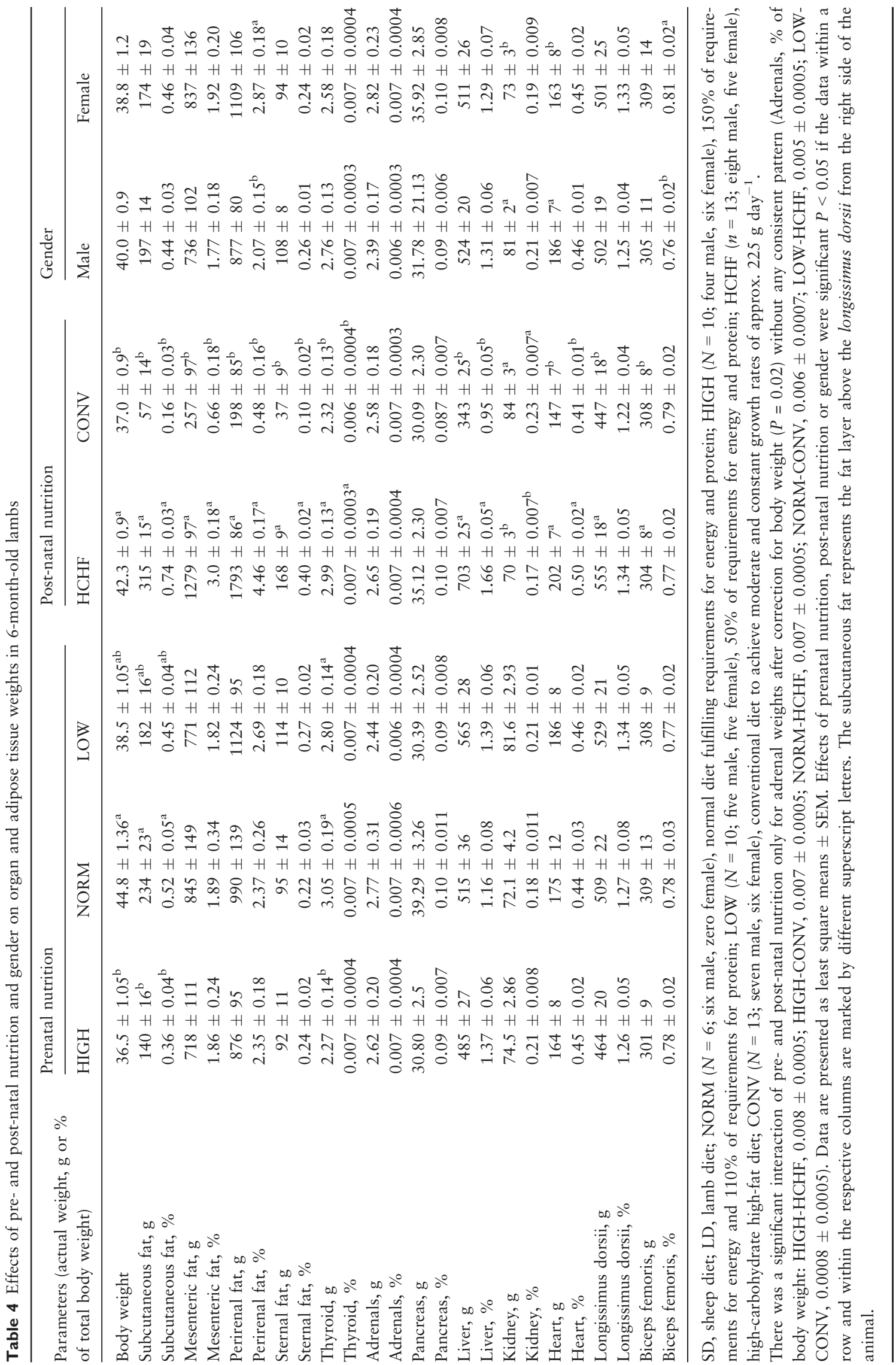


Figure 5 Changes in ratios of subcutaneous to mesenteric $(a, b)$, subcutaneous to peri-renal $(c, d)$ and mesenteric to peri-renal $(e, f)$ fat deposition at postmortem. HIGH ( $N=10$; four male, six female); NORM ( $N=6$; six male, zero female), LOW ( $N=10$; five male, five female); $\operatorname{HCHF}(N=13$; eight male, five female) and $\operatorname{CONV}(N=13$; seven male, six female): see legends to Figure 1. The subcutaneous fat represents fat above the longissimus dorsii from the right side of the animal. Values are least square (LS) means \pm SEM represented by vertical bars were significantly different at $* P<0.05 ; * * * P<0.0001$.
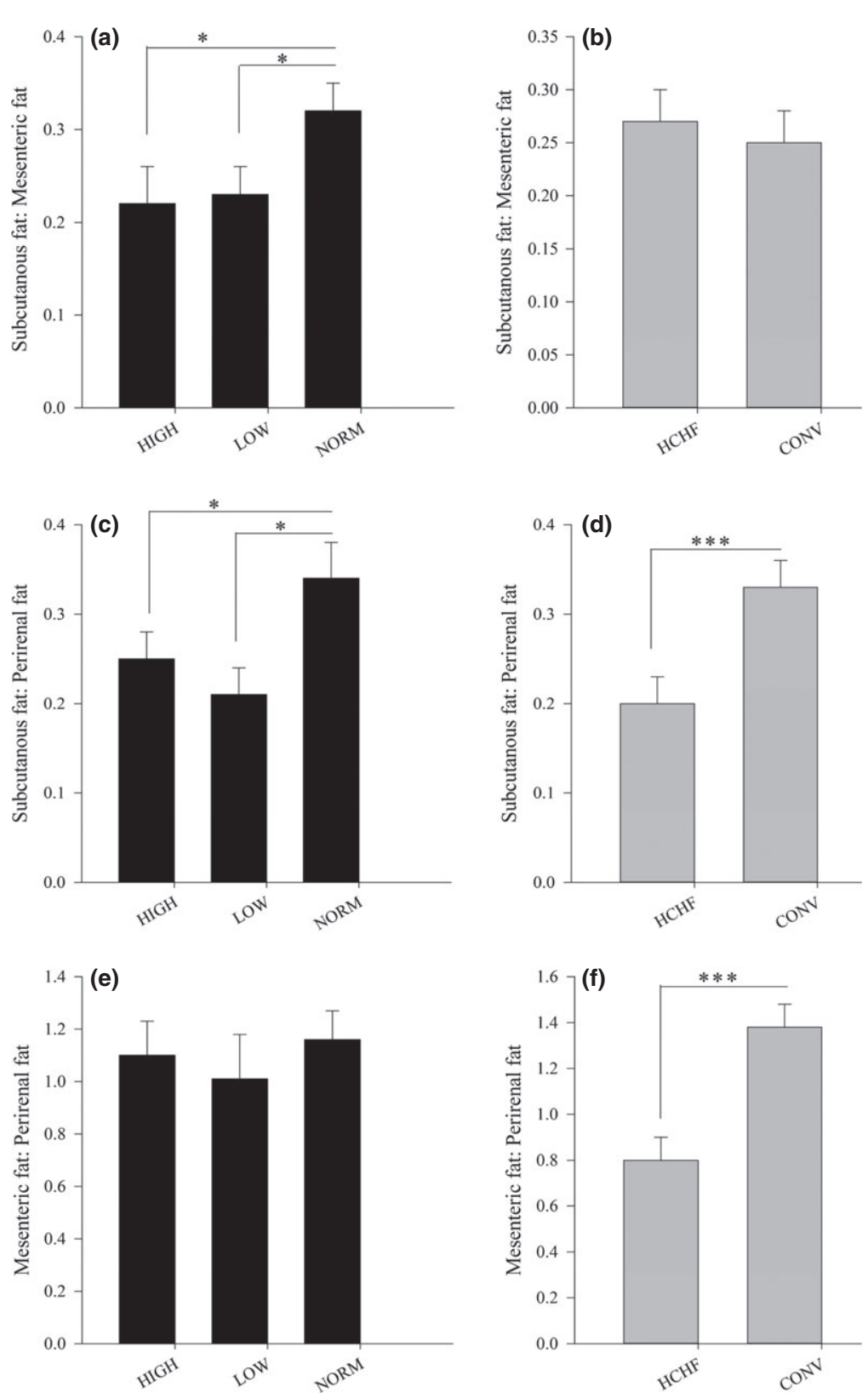

similar impacts on growth and development, and physiological function in 6-month-old sheep offspring. The major findings of this study were that (i) exposure to widely different types of malnutrition (either overnutrition or undernutrition) in late gestation can depress expandability of the subcutaneous adipose tissue in post-natal life thereby predisposing for development of visceral adiposity later in life upon exposure to an obesogenic diet, (ii) renal fat may be a possible target of post-natally induced obesity, and this is co-manifested with depressed kidney development, and (iii) metabolic adaptability to variations in nutrient supply during fasting is differentially programmed in response to late gestation exposure to over- as compared to undernutrition.
When evaluating the results from the present study, it should be borne in mind that pre- and post-natal nutrition and gender-specific effects could be evaluated based on all data from all animals from all groups for growth, morphometric measurements, feed intake and metabolic and endocrine responses during fasting, whereas slaughter data were obtained from smaller subgroups of animals, and gender effects could only be evaluated for the LOW and HIGH prenatal groups.

\section{Prenatal under- and overnutrition resulted in similar alterations in regional fat-distribution patterns}

Regional distribution of adipose tissue plays a vital role in understanding how obesity is related to distur- 
bances in carbohydrate and lipid metabolism (Bouchard et al. 1993). In humans, the site of fat accumulation can play a central role regarding the health risks and disorders associated with obesity. Several studies have reported that abdominal fat is a particularly important risk factor for the development of obesity-related complications such as the metabolic syndrome (Wajchenberg 2000). Subcutaneous fat on the other hand has been suggested to be a 'healthy' fat, and increased amounts of subcutaneous fat has been associated with improved insulin sensitivity and decreased risk of developing type 2 diabetes (Misra et al. 1997, Snijder et al. 2003). The healthy features of subcutaneous fat have further been verified by transplanting subcutaneous fat into the visceral area in mice. In such studies, subcutaneous fat was shown to have unique intrinsic properties, which provided beneficial effects such as improved control of body weight as well as improvements of whole body insulin sensitivity and glucose metabolism (Tran et al. 2008). These studies strongly indicate that subcutaneous fat may behave as a 'healthy' fat depot compared to visceral fat, which is not simply due to the anatomical location, but also due to depot-specific intrinsic properties.

In the present study, we found that late gestation overnutrition just as undernutrition (Nielsen et al. 2012) interferes with subcutaneous adipose tissue function resulting in decreased ability or preference to accumulate fat in the subcutaneous area. Completely different types of exposures in late gestation may, therefore, lead to the same adverse outcomes later in life and alter fat-distribution patterns in a way, which can increase the risk of abdominal fat deposition and obesity-induced metabolic disorders. This agrees with the previously reported U-shaped relationship between birth weight and obesity risk later in life (Curhan et al. 1996, Godfrey \& Barker 2000, Dyer \& Rosenfeld 2011). Abdominal obesity is considered a marker of adipose dysfunction and the most prevalent indicator for development of metabolic disorders (Despres $\&$ Lemieux 2006). It has been shown in overweight and obese women that changes in fat deposition in legs were negatively correlated with risk factors of coronary heart disease, whereas truncal fat deposition was positively correlated with these risk factors, suggesting that relocation from central to peripheral fat deposition is important to reduce the coronary heart disease risk (Okura et al. 2004). Excess accumulation of abdominal fat has been related to poor expandability of subcutaneous fat, as this can reduce the ability of subcutaneous adipose tissue to act as a buffer, that is, 'sink', in situations with excessive availability of energy and nutrients (Lemieux 2004), and thereby the risk of nutrient overflow leading to increased abdominal and ectopic fat deposition (Miranda et al. 2005) is increased. Further investigations are needed to uncover the underlying mechanisms explaining why prenatal malnutrition both in the form of overand undernutrition leads to a lowered fat-deposition capacity in the subcutaneous area, and to determine whether it is simply due to alterations in the subcutaneous adipose tissue, or whether modifications of metabolic and endocrine functions of other fat depots are involved as well.

\section{Renal fat as a possible target of post-natally induced obesity, and co-manifestation with depression of kidney development}

In our study, the post-natal HCHF diet enormously increased peri-renal fat deposition (by a factor of 9) regardless of the prenatal nutrition. The early postnatal high-fat diet appeared to have the peri-renal area as a primary target, as fat deposition in this area was favoured relative to deposition in the other fat depots studied.

Abdominal fat accumulation is proposed to be a major determinant for the increased risk of chronic kidney, cardiovascular and metabolic diseases associated with obesity-induced metabolic syndrome (Chen et al. 2004). Previous studies have suggested that NEFA and adipokines released by visceral adipose tissue play a central role in the development of organ dysfunctions and metabolic disorders in obese individuals (Kahn et al. 2006). When lipid droplets are accumulated in non-adipose tissues (ectopic fat deposition), then it may lead to cellular dysfunctions or even cell death due to lipotoxicity (Unger \& Orci 2001). To what extent peri-renal fat contributes to these adverse impacts of abdominal adipose tissue in humans on development of metabolic disorders and organ dysfunction remains to be established.

We have both in this study, where male and female lambs were studied, and in a previous sheep study including only male lambs (Nielsen et al. 2012), found that kidney weights can be substantially reduced by exposure to an early post-natal HCHF diet. This could simply be a consequence of limitations in amino acids supply and hence inability to sustain normal development of the organ, as dietary protein content of the HCHF diet was quite low and not fulfilling normal requirements for protein (see Table 3). However, for none of the other organs or tissues did we observe any indication of a similar depressive effect of the HCHF diet on their development and gross weights in the 6-month-old lambs. This was even true for the skeletal muscles, biceps femoris and longissimus dorsii, and it proves to show that there are strong compensatory mechanisms enabling the body to 
improve the efficiency of amino acid utilization for protein synthesis and deposition, when energy supply is abundant, presumably through depression of their entry into catabolic pathways. In support of this, we observed much lower plasma levels of BUN in HCHFfed as compared to CONV-fed lambs, indicating lower rates of amino acid oxidation particularly during fasting. We therefore raise the question, whether the reduced kidney development in HCHF lambs could be related to the excessive peri-renal fat deposition? In diabetic patients, it has in fact been shown that peri-renal fat expansion irrespective of general adiposity can be an independent risk factor for kidney dysfunction, although the mechanism is still not clear, but both physical compression or adipose secretion of locally acting substances have been suggested as possible mechanisms (Lamacchia et al. 2011). In our HCHF lambs, we also observed much higher levels of plasma creatinine (approx. $50 \%$ ), which is considered a rough index of glomerular filtration rate and hence kidney function (Perrone et al. 1992). Plasma creatinine levels can be influenced by other body characteristics as well, and it is known to correlate with total gross muscle mass (Perrone et al. 1992). However, there were no indications suggesting that muscle mass should have been decreased in the HCHF compared to the CONV lambs. The scientific information on peri-renal fat is remarkably scarce, and it has not been possible to find information on the specific metabolic and physiological functions of perirenal fat relative to other visceral fats, including such aspects as vascular perfusion and drainage and thus potential routes for direct impacts of peri-renal fat on other organ systems in the body. Future studies appear to be needed to elucidate the potential role of peri-renal fat for kidney development.

Some of the HCHF-fed lambs stood out from the rest of the lambs fed this diet. They did not grow well and attained a smaller body size and skinny appearance at 6 months of age (around puberty). These 'small-skinny-fat' animals appeared to have lower plasma levels of creatinine, which corresponds with a lower muscle mass, and lower plasma IGF-1 levels, corresponding to their lower dietary energy and protein intake. But they also had lower plasma leptin levels irrespective of the fact that they had similar quantitative accumulation of fat as the other HCHF lambs and mainly in the peri-renal area. A 'lean obese' phenotype has been reported in humans, such as the Pima Indians, who have a high proportion of their body mass located in the abdominal area, and they are known to be more prone to development of peripheral insulin insensitivity and earlier in life (Abbott \& Foley 1987). Future studies are required to reveal if our 'small-skinny-fat' sheep potentially could represent an animal model for the human 'lean obese' phenotype, and the potential role of peri-renal obesity and altered leptin regulation in the development of such a phenotype.

\section{Adaptation of glucose-insulin homoeostasis during fasting is differentially programmed by late gestation over- vs. undernutrition}

With our post-natal HCHF feeding, we were able to produce obese lambs with distinct metabolic and endocrine profiles compared to CONV lambs. In humans, there is a strong relationship between a highfat diet and development of pancreatic $\beta$-cell failure, insulin resistance and type 2 diabetes (Cerf 2007). The HCHF lambs in our studies became hyperglycaemic, hypercholesterolaemic and hyperlipidaemic with very high NEFA levels, and prolonged exposure of such high levels of free fatty acids has been shown to have cytostatic (reduced glucose stimulated insulin secretion) and proapoptotic effects (caspase mediated) on human pancreatic $\beta$-cells in vitro (Lupi et al. 2002). In the present study, the lambs fed a high-fat diet in early post-natal life generally showed signs of reduced glucose tolerance with higher glucose and insulin (except in LOW-HCHF lambs) levels in the fed state, and also higher glucose levels during fasting, although the animals were able to suppress glucose levels during fasting as efficiently as were the CONV lambs. The HIGH lambs with a history of foetal overnutrition attained higher blood glucose levels upon exposure to the HCHF diet compared to LOW lambs, whereas NORM lambs had intermediate glucose levels, and these differences between HIGH and LOW lambs persisted throughout the fasting period. This does not lend support to our hypothesis that individuals with a foetal history of overnutrition will have a superior ability to cope with a high-fat diet in early post-natal life. The data presented here do not allow us to distinguish exactly where in the glucose-insulin axis, the foetally induced alterations occurred. We are conducting more detailed investigations as part of this study to address these issues. However, the outcomes from the current study may point to differential programming of the mechanisms involved in glucoseinsulin homoeostasis by prenatal undernutrition as compared to overnutrition, where HIGH become hyperglycaemic with an apparently lowered peripheral insulin sensitivity, whereas LOW lambs appeared to be more resistant to the hyperglycaemic effect of the HCHF diet, even though they had the lowest insulin levels of the three groups of HCHF-fed lambs.

We did not find any indications that prenatal nutrition exposures would influence adaptability of lipid metabolism, that is, NEFA, TG, BOHB and choles- 
terol levels or regulatory factors, that is, IGF-1 and leptin in the young lambs, as these parameters were exclusively affected by the post-natal diet.

In conclusion, prenatal overnutrition just as undernutrition predisposed for abdominal adiposity, apparently by reducing the expandability of subcutaneous adipose tissue. When prenatal effects were observed, they were in general additive to post-natal nutrition effects. Renal fat appeared to be a special target of post-natal overnutrition, and future studies are needed to reveal whether the comanifestation of excessive fat deposition in the peri-renal area with reduced kidney development and function reflects a causal relationship. Exposure to gestational overnutrition did not provide a protective effect against development of hyperglycaemia later in life. Although prenatal over- and undernutrition resulted in similar changes in adipose deposition patterns, they may have differential impacts on underlying regulatory systems such as glucoseinsulin homoeostasis.

\section{Conflict of interest}

The authors declare that they have no conflict of interest.

The study was part of the research programme of the Centre for Foetal Programming (CFP), Denmark. The CFP was supported by the Danish Council for Strategic Research (grant 09067124). Authors would like to thank Dennis S. Jensen, MariLouise D. Andersen and Vibeke G. Christensen for their expert technical assistance. Authors would also like to acknowledge Niels Bodilsen and Valery Sobe for their valuable assistance in feeding and caring of animals. Authors wish to thank Mark Birtwistle (PhD student, UK) for his help during challenge test and slaughtering. The authors would also like to acknowledge Cecilie Jæger Leidersdorff, Ida Marie Steensen, Lei Hou and Marina Kjærgaard for their valuable help with handling of animals and blood samplings during challenge tests.

\section{References}

Abbott, W.G. \& Foley, J.E. 1987. Comparison of body composition, adipocyte size, and glucose and insulin concentrations in Pima Indian and Caucasian children. Metabolism 36, 576-579.

Beausoleil, N.J., Blache, D., Stafford, K.J., Mellor, D.J. \& Noble, A.D.L. 2008. Exploring the basis of divergent selection for 'temperament' in domestic sheep. Appl Anim Behav Sci 109, 261-274.

Blache, D., Tellam, R.L., Chagas, L.M., Blackberry, M.A., Vercoe, P.E. \& Martin, G.B. 2000. Level of nutrition affects leptin concentrations in plasma and cerebrospinal fluid in sheep. J Endocrinol 165, 625-637.

Bouchard, C., Despres, J.P. \& Mauriege, P. 1993. Genetic and nongenetic determinants of regional fat distribution. Endocr Rev 14, 72-93.
Breier, B.H., Gallaher, B.W. \& Gluckman, P.D. 1991. Radioimmunoassay for insulin-like growth factor-I: solutions to some potential problems and pitfalls. J Endocrinol 128, 347-357.

Cerf, M.E. 2007. High fat diet modulation of glucose sensing in the beta-cell. Med Sci Monit 13, RA12-RA17.

Chen, J., Muntner, P., Hamm, L.L., Jones, D.W., Batuman, V., Fonseca, V., Whelton, P.K. \& He, J. 2004. The metabolic syndrome and chronic kidney disease in U.S. adults. Ann Intern Med 140, 167-174.

Curhan, G.C., Chertow, G.M., Willett, W.C., Spiegelman, D., Colditz, G.A., Manson, J.E., Speizer, F.E. \& Stampfer, M.J. 1996. Birth weight and adult hypertension and obesity in women. Circulation 94, 1310-1315.

Despres, J.P. \& Lemieux, I. 2006. Abdominal obesity and metabolic syndrome. Nature 444, 881-887.

Dyer, J.S. \& Rosenfeld, C.R. 2011. Metabolic imprinting by prenatal, perinatal, and postnatal overnutrition: a review. Semin Reprod Med 29, 266-276.

Ford, S.P. \& Long, N.M. 2011. Evidence for similar changes in offspring phenotype following either maternal undernutrition or overnutrition: potential impact on fetal epigenetic mechanisms. Reprod Fertil Dev 24, 105-111.

Ford, S.P., Hess, B.W., Schwope, M.M., Nijland, M.J., Gilbert, J.S., Vonnahme, K.A., Means, W.J., Han, H. \& Nathanielsz, P.W. 2007. Maternal undernutrition during early to mid-gestation in the ewe results in altered growth, adiposity, and glucose tolerance in male offspring. J Anim Sci 85, 1285-1294.

Godfrey, K.M. \& Barker, D.J. 2000. Fetal nutrition and adult disease. Am J Clin Nutr 71, 1344S-1352S.

Grattan, D.R. 2008. Fetal programming from maternal obesity: eating too much for two? Endocrinology 149, 5345-5347.

Guilloteau, P., Zabielski, R., Hammon, H.M. \& Metges, C.C. 2009. Adverse effects of nutritional programming during prenatal and early postnatal life, some aspects of regulation and potential prevention and treatments. J Physiol Pharmacol 60, 17-35.

Hales, C.N. \& Barker, D.J. 1992. Type 2 (non-insulin-dependent) diabetes mellitus: the thrifty phenotype hypothesis. Diabetologia 35, 595-601.

Husted, S.M., Nielsen, M.O., Tygesen, M.P., Kiani, A., Blache, D. \& Ingvartsen, K.L. 2007. Programming of intermediate metabolism in young lambs affected by late gestational maternal undernourishment. Am J Physiol Endocrinol Metab 293, E548-E557.

Kahn, S.E., Hull, R.L. \& Utzschneider, K.M. 2006. Mechanisms linking obesity to insulin resistance and type 2 diabetes. Nature 444, 840-846.

Kongsted, A.H., Tygesen, M.P., Husted, S.V., Oliver, M.H., Tolver, A., Christensen, V.G., Nielsen, J.H. \& Nielsen, M.O. 2013. Programming of the glucose-insulin homeostasis: long-term consequences of prenatal versus early postnatal nutrition insults. Evidence from a sheep model. Acta Physiol, doi: 10.1111/apha.12080 [early view].

Lamacchia, O., Nicastro, V., Camarchio, D., Valente, U., Grisorio, R., Gesualdo, L. \& Cignarelli, M. 2011. Paraand perirenal fat thickness is an independent predictor of chronic kidney disease, increased renal resistance index 
and hyperuricaemia in type-2 diabetic patients. Nephrol Dial Transplant 26, 892-898.

Lemieux, I. 2004. Energy partitioning in gluteal-femoral fat: does the metabolic fate of triglycerides affect coronary heart disease risk? Arterioscler Thromb Vasc Biol 24, 795-797.

Lupi, R., Dotta, F., Marselli, L., Del Guerra, S., Masini, M., Santangelo, C., Patane, G., Boggi, U., Piro, S., Anello, M., Bergamini, E., Mosca, F., Di Mario, U., Del Prato, S. \& Marchetti, P. 2002. Prolonged exposure to free fatty acids has cytostatic and pro-apoptotic effects on human pancreatic islets: evidence that beta-cell death is caspase mediated, partially dependent on ceramide pathway, and Bcl-2 regulated. Diabetes 51, 1437-1442.

Miller, D.R., Jackson, R.B., Blache, D. \& Roche, J.R. 2009. Metabolic maturity at birth and neonate lamb survival and growth: the effects of maternal low-dose dexamethasone treatment. J Anim Sci 87, 3167-3178.

Miranda, P.J., DeFronzo, R.A., Califf, R.M. \& Guyton, J.R. 2005. Metabolic syndrome: definition, pathophysiology, and mechanisms. Am Heart J 149, 33-45.

Misra, A., Garg, A., Abate, N., Peshock, R.M., Stray-Gundersen, J. \& Grundy, S.M. 1997. Relationship of anterior and posterior subcutaneous abdominal fat to insulin sensitivity in nondiabetic men. Obes Res 5, 93-99.

Muhlhausler, B.S., Adam, C.L., Findlay, P.A., Duffield, J.A. \& McMillen, I.C. 2006. Increased maternal nutrition alters development of the appetite-regulating network in the brain. FASEB J 20, 1257-1259.

Nielsen, M.O., Kongsted, A.H., Thygesen, M.P., Strathe, A.B., Caddy, S., Quistorff, B., Jorgensen, W., Christensen, V.G., Husted, S., Chwalibog, A., Sejrsen, K., Purup, S., Svalastoga, E., McEvoy, F.J. \& Johnsen, L. 2012. Late gestation undernutrition can predispose for visceral adiposity by altering fat distribution patterns and increasing the preference for a high-fat diet in early postnatal life. $\mathrm{Br} J \mathrm{Nutr}$, 109, 2098-2110.
NRC 2007. Nutrient Requirements for Small Ruminants. The National Academies Press, Washington, DC.

Okura, T., Nakata, Y., Yamabuki, K. \& Tanaka, K. 2004. Regional body composition changes exhibit opposing effects on coronary heart disease risk factors. Arterioscler Thromb Vasc Biol 24, 923-929.

Patel, M.S. \& Srinivasan, M. 2011. Metabolic programming in the immediate postnatal life. Ann Nutr Metab 58, $18-28$.

Perrone, R.D., Madias, N.E. \& Levey, A.S. 1992. Serum creatinine as an index of renal function: new insights into old concepts. Clin Chem 38, 1933-1953.

Ravelli, A.C., van Der Meulen, J.H., Osmond, C., Barker, D.J. \& Bleker, O.P. 1999. Obesity at the age of $50 \mathrm{y}$ in men and women exposed to famine prenatally. Am J Clin Nutr 70, 811-816.

Snijder, M.B., Dekker, J.M., Visser, M., Bouter, L.M., Stehouwer, C.D., Kostense, P.J., Yudkin, J.S., Heine, R.J., Nijpels, G. \& Seidell, J.C. 2003. Associations of hip and thigh circumferences independent of waist circumference with the incidence of type 2 diabetes: the Hoorn Study. Am J Clin Nutr 77, 1192-1197.

Symonds, M.E. \& Lomax, M.A. 1992. Maternal and environmental influences on thermoregulation in the neonate. Proc Nutr Soc 51, 165-172.

Tran, T.T., Yamamoto, Y., Gesta, S. \& Kahn, C.R. 2008. Beneficial effects of subcutaneous fat transplantation on metabolism. Cell Metab 7, 410-420.

Unger, R.H. \& Orci, L. 2001. Diseases of liporegulation: new perspective on obesity and related disorders. FASEB $J$ $15,312-321$.

Wajchenberg, B.L. 2000. Subcutaneous and visceral adipose tissue: their relation to the metabolic syndrome. Endocr Rev 21, 697-738. 